\title{
UMA REVISÃO DA LITERATURA SOBRE TRANSFERÊNCIA DE TECNOLOGIA
}

\author{
Karla Motta', Monica Luna ${ }^{2}$, Jerônimo Santos ${ }^{3}$, Fernando Romero ${ }^{4}$ \\ ${ }_{1,2}$ Universidade Federal de Santa Catarina-UFSC, Programa de Pós-Graduação em Engenharia de Produção \\ ${ }^{1,3}$ Instituto Federal de Educação, Ciência e Tecnologia do Rio Grande do Norte \\ ${ }^{3,4}$ Universidade do Minho-EE UMINHO, Programa Doutoral Engenharia Industrial e Sistemas \\ karla.motta@ifrn.edu.br1, monica.luna@ufsc.br ${ }^{2}$, jeronimo@ifrn.edu.br ${ }^{3}$,fromero@dps.uminho.pt ${ }^{4}$
}

Submetido em 26/04/2016 - Aceito em 14/12/2016

DOI: $10.15628 /$ holos.2016.2792

\section{RESUMO}

Este trabalho apresenta uma revisão da literatura sobre transferência de tecnologia, com o objetivo de identificar e caracterizar abordagens sobre o tema. Quanto à metodologia adotada, tal revisão é de natureza integrativa e de cunho bibliográfico, temático, histórico e analítico. Os conteúdos pesquisados estão apresentados conforme uma estrutura taxonômica identificada na literatura, a qual foi adaptada, com base nos estudos consultados. Conclui-se que há na literatura uma convergência na estrutura dos conceitos de tecnologia e transferência de tecnologia, cuja evolução no tempo não gerou alterações. Verifica-se que não existem nos estudos observados uma consolidação das características promotoras da efetividade da transferência de tecnologia, ou dos obstáculos a transpor neste processo. É observado que os trabalhos analisados não incluem a totalidade dos demais componentes do processo identificados nesta revisão, tais como atores, estratégia e projetos para acesso à tecnologia, os quais são abordados de modo disperso e pontual. No estudo observa-se ainda que as diferentes tipologias de transferência de conhecimento apresentadas na literatura estão relacionadas aos atores que promovem a transferência, ou seja, o receptor, o emissor e os facilitadores, sendo aqui destacadas as suas correlações. No âmbito dos estudos analisados, esta revisão se propõe a indicar as referidas lacunas literárias, direcionando futuras pesquisas sobre o tema.

PALAVRAS-CHAVE: Tecnologia, Transferência de tecnologia, Taxonomia, Revisão da Literatura.

\section{TECHNOLOGY TRANSFER LITERATURE REVIEW}

\section{ABSTRACT}

This paper presents a review of the literature on technology transfer, aiming to identify and to characterize the subject approaches. As for methodology, such a review is integrative nature and literature, thematic, historical and analytical. The searched contents are presented according to a taxonomic structure identified in the literature, which was adapted based on reviewed studies. We conclude that in the literature there is a convergence in the structure of the concepts of technology and technology transfer, whose evolution over time did not generate changes. It appears that there are no studies observed a consolidation of features promoting the effectiveness of technology transfer, or of obstacles to overcome in this process. Papers analyzed do not include all the other components of the process identified in this review, such as actors, strategy and projects for access to technology, which are addressed in scattered and piecemeal fashion. In the study, we could observe that different types of knowledge transfer presented in the literature are related to the actors that promote the transfer, like the receiver, the transmitter and facilitators, and their correlations highlighted here. As part of the analyzed studies, this review aims to highlight those gaps in the literature, directing future research on the topic.

KEY-WORDS: Technology, Technology transfer, Taxonomy, Literature Review. 


\section{INTRODUÇÃO}

O crescimento econômico sustentado figura na lista de prioridades das nações desenvolvidas e em desenvolvimento, relacionando-se diretamente com a capacidade de inovação (Varsakelis, 2006). O desempenho referente à inovação nas empresas sofre influência da formulação de estratégias viáveis para transferência de tecnologia, segundo Guan, Mok, Yam e Pun (2006), em estudo realizado com 1590 MPEs indústrias chinesas. Albors-Garrigos, Zabaleta e Ganzarain (2010) corroboram com esta opinião, a partir de pesquisa realizada sobre o sistema de inovação do País Basco, de onde concluem que a estratégia deve focar a gestão da transferência de tecnologia, propriamente dita, e dos relacionamentos nela existentes. Observando a situação brasileira referente à transferência de tecnologia, Pires e Quintella (2015) indicam a necessidade do planejamento e estratégias que permitam promover uma política mais efetiva, que possa ampliar a interação da universidade com a indústria, o governo e outras instituições de ciência e tecnologia. Desta forma, mostra-se relevante a necessidade de mapear os componentes de uma abordagem para a transferência de tecnologia, a ser incorporada à estratégia das organizações inovativas. Nesse contexto, este trabalho tem como objetivo principal identificar o estado da arte sobre transferência de tecnologia, identificando e caracterizando abordagens sobre o tema, com base na literatura. Uma taxonomia para transferência de tecnologia é estruturada a partir dos principais conceitos e componentes referentes à temática, apoiada em uma proposição de Reisman (2005) e em decorrência da pesquisa realizada para a elaboração deste estudo. Os critérios metodológicos adotados para elaboração do estudo são esclarecidos a seguir. As seções seguintes discorrem sobre conceitos, atores, estratégia e projeto para transferência de tecnologia, sendo o artigo encerrado com algumas considerações sobre o levantamento realizado e recomendações de futuros estudos.

\section{METODOLOGIA DA PESQUISA}

A revisão de literatura pode ser classificada conforme seu propósito, abrangência, função e tipo de análise desenvolvida, segundo Noronha e Ferreira (2000). No que tange ao propósito, a presente revisão é analítica, na medida em que aborda um tema específico, reunindo os vários desenvolvimentos realizados sobre transferência de tecnologia. Referente à abrangência, este estudo se trata de uma revisão temática, centrada no recorte específico que versa sobre as propostas de modelos para transferência de tecnologia e fatores a ele pertinentes. Em termos da função, este trabalho é de caráter histórico, por reunir a literatura referente a um tema, contida em um intervalo de tempo determinado, possibilitando comparar a evolução das informações advindas de distintas fontes. Quanto ao tipo de análise empregada para a revisão, o trabalho é crítico, na medida em que avalia e compara os estudos que versam sobre transferência de tecnologia.

Segundo Reisman (2005, p. 199) “Um bom esquema taxonômico é indispensável para uma efetiva revisão da literatura e especialmente para a eficiência da sua apresentação." Com 
o objetivo de ordenar o conteúdo da revisão da literatura realizada neste estudo, foi elaborado um esquema taxonômico referente a transferência de tecnologia, conforme apresentado no quadro 1.

\begin{tabular}{|l|l|l|}
\hline \multicolumn{1}{|c|}{ 1. ATORES } & \multicolumn{1}{|c|}{ 2. ESTRATÉGIA } & \multicolumn{1}{c|}{ 3. PROJETO } \\
\hline 1.1. Emissor ou Fonte & 2.1. Governança & 3.1. Gestão \\
\hline 1.2. Receptor ou Destinatário & 2.2. Motivação dos atores & $\begin{array}{l}\text { 3.2. Mecanismos de relacionamento ou tipos de } \\
\text { transação }\end{array}$ \\
\hline 1.3 Agentes de colaboração e apoio & 2.3. Obstáculos & 3.3. Conteúdo tecnológico \\
\hline & 2.4. Fatores de efetividade & 3.4. Processo operacional \\
\hline & 2.5. Parcerias & 3.5. Monitoramento e avaliação do desempenho \\
\hline & & 3.6. Viabilidade \\
\hline
\end{tabular}

Quadro 1: Taxonomia para transferência de tecnologia adotada neste estudo

A partir da literatura revisada, em alinhamento à linha metodológica estabelecida e à estrutura taxonômica elaborada, seguem apresentados os resultados obtidos, referentes à temática da transferência de tecnologia.

\section{RESULTADOS E DISCUSSÃO}

Serão agora apresentados os resultados do levantamento bibliográfico efetuado, alinhados à estrutura taxonômica proposta. Ao procurar apreender o significado do termo tecnologia, verificou-se que para Burgelman, Christensen e Wheelwrigth (2012) os componentes "habilidades" e "artefatos teóricos e práticos" fazem parte da tecnologia, uma vez que podem ser utilizados para desenvolver produtos e serviços em organizações, ou ainda para produzir e fornecer esses produtos e serviços. Uma conceituação estrutural para tecnologia é apresentada pela ANPROTEC e SEBRAE (2002), onde o termo implica o que, por quem, por quê, para quem e como fazer. Esses Institutos afirmam que tecnologia se refere às técnicas, métodos, procedimentos, ferramentas, equipamentos e instalações que concorrem para a realização e obtenção de um ou vários produtos.

O segundo conceito verificado neste estudo é o de transferência de tecnologia. Para cumprir o objetivo de suprir as necessidades e desejos da sociedade, as empresas utilizam tecnologias para desenvolverem bens e serviços, de modo a alcançarem a continuidade dos negócios. Segundo Reisman (2005), a busca por competitividade leva as organizações a procurarem aumentar sua produtividade e desempenho comercial, o que se dá por meio do aperfeiçoamento de métodos de trabalho e de fatores de produção. Essas modificações tanto podem advir do ambiente organizacional interno, sendo desenvolvidas por equipes próprias, quanto de fontes externas (Kremer, 2007), mediante fenômeno denominado transferência de 
tecnologia. Em conformidade com a revisão conceitual realizada, seguem apresentadas as abordagens realizadas aos atores da transferência de tecnologia na literatura consultada.

\subsection{Atores da transferência de tecnologia}

Os principais atores da transferência de tecnologia são o emissor ou fonte e o receptor ou destinatário, existindo ainda outros agentes facilitadores do processo. Exemplos destes atores estão apresentados no quadro 2.

\begin{tabular}{c|l|c}
\hline ATOR & \multicolumn{1}{|c|}{ COMPONENTES } & $\begin{array}{c}\text { AUTOR/ } \\
\text { ANO }\end{array}$ \\
\hline $\begin{array}{c}\text { Emissor ou } \\
\text { Fonte }\end{array}$ & $\begin{array}{l}\text { Universidade, centros de pesquisa públicos e privados, bases de } \\
\text { patentes, Internet, empresas de consultoria, fornecedores, } \\
\text { concorrentes, exposições, conferências e encontros setoriais, } \\
\text { empresas do mesmo grupo, interior da própria empresa e clientes }\end{array}$ & $\begin{array}{c}\text { Caputo, Cucchiella, Fratocchi, } \\
\text { (2004) }\end{array}$ \\
\hline $\begin{array}{l}\text { Receptor ou } \\
\text { destinatário }\end{array}$ & $\begin{array}{l}\text { Interessados em receber uma nova tecnologia e desenvolvê-la, } \\
\text { podendo pertencer ao mesmo Estado soberano ou a nações } \\
\text { distintas }\end{array}$ & $\begin{array}{c}\text { Bauer (2003); Rodrigues (2008); } \\
\text { Rodrigues e Estorilio (2012) }\end{array}$ \\
\hline $\begin{array}{l}\text { Promotores e } \\
\text { facilitadores }\end{array}$ & $\begin{array}{l}\text { Quadro político e institucional, intermediários situados no entorno } \\
\text { das empresas; investidores de risco e fundos de inovação e o } \\
\text { Governo }\end{array}$ & $\begin{array}{l}\text { Thorpe, Holt, Macpherson e Pittaway } \\
\text { (2005); Caputo et al. (2004); Yokakul e } \\
\text { Zawdie (2009); Thorpe et al. (2005); } \\
\text { Lee e Win (2004); Jones (2003) }\end{array}$ \\
\hline
\end{tabular}

\section{Quadro 2 - Atores da transferência de tecnologia}

Fonte: Elaboração própria a partir dos autores referenciados

A configuração das interações entre emissores, receptores e facilitadores pode assumir diversos formatos, conforme a estratégia adotada para a transferência de tecnologia.

\subsection{Estratégia para transferência de tecnologia}

Os principais componentes identificados na literatura que se referem à estratégia para transferência de tecnologia foram governança, motivação dos atores, obstáculos, fatores de efetividade e parcerias.

\section{- Governança}

O modo de governança é relevante para a estratégia da transferência de tecnologia, diante da necessidade de definir uma estrutura organizacional para os relacionamentos entre os atores do processo, conforme é ressaltado por O'Dwyer e O'Flynn (2005). A clara definição dos papeis a serem desempenhados pelos atores do processo em muito contribui para a sua efetividade (Perkmann \& Walsh, 2007). Dentre as etapas da governança, constam o alinhamento de culturas corporativas, políticas de trabalho e procedimentos operacionais entre parceiros, de modo que haja a efetiva transferência de tecnologia (Lakpetch \& Lorsuwannarat, 2012). Neste alinhamento devem ser considerados atores, tipos de transação 
e motivações (Reisman, 2005), assim como a eficiência dos sistemas político, jurídico governamental e educacional (Varsakelis, 2006).

- Motivação dos atores

As motivações dos atores principais e complementares são um fator crítico pra o sucesso da transferência de tecnologia, destacando-se dentre elas o verdadeiro interesse do receptor em adotar a tecnologia transferida (Lakpetch \& Lorsuwannarat, 2012). As motivações identificadas na literatura estão consolidadas no quadro 3.

\begin{tabular}{|c|c|}
\hline ATOR & MOTIVAÇÕES \\
\hline MPEs & $\begin{array}{l}\text { Baixo custo ou disponibilidade de financiamento do processo, agilidade e facilidade na implantação, clara } \\
\text { percepção dos potenciais retornos (Caputo et al., 2004) }\end{array}$ \\
\hline $\begin{array}{l}\text { Empresas de } \\
\text { grande porte }\end{array}$ & $\begin{array}{l}\text { Retornos de investimentos em P\&D e possibilidade de tornar MPEs mais competitivas e fazer delas suas } \\
\text { fornecedoras (Caputo et al., 2004); desejo de se tornarem líderes tecnológicos (Venters \& Kyriakidou- } \\
\text { Zacharoudiou, 2012) }\end{array}$ \\
\hline Universidade & $\begin{array}{l}\text { Impacto do projeto na área de atuação e possibilidade de ver teorias aplicadas na prática (Venters \& } \\
\text { Kyriakidou-Zacharoudiou, 2012); incentivo da legislação, ganho de royalties, pagamento de royalties aos } \\
\text { inventores, publicidade positiva, suporte financeiro para pesquisa, satisfação com a disseminação das } \\
\text { tecnologias, recrutamento e retenção da equipe (Decter, Bennett \& Leseure, 2007); financiamento de } \\
\text { pesquisas e oportunidades de aprendizagem prática para os alunos (Elmuti, Abebe, Nicolosi \& Dealtry, } \\
\text { 2005); colocação de estudantes no ambiente industrial, desenvolvimento de atividades geradoras de renda, } \\
\text { acesso à indústria para realização de pesquisa fundamental e aplicada, ingresso em mercados protegidos, } \\
\text { aprimoramento do nível de negócios, melhoria na execução de novas tecnologias, estabelecimento de boa } \\
\text { vontade bilateral, desenvolvimento de novos produtos e spin-off, redução de custos de produção e } \\
\text { patenteamento (Lee \& Win, 2004). }\end{array}$ \\
\hline
\end{tabular}

Governo

Promoção da igualdade em diferentes regiões e o incremento da competitividade do país no nível mundial (Caputo et al., 2004)

\section{Quadro 3 - Motivações dos atores da transferência de tecnologia Fonte: Elaboração própria a partir dos autores referenciados}

Não obstante as motivações identificadas, há na literatura registros de obstáculos a considerar na transferência de tecnologia, os quais seguem indicados.

\section{- Obstáculos}

Observa-se na literatura que o processo de transferência de tecnologia requer enfrentamento de obstáculos culturais, cognitivos, estruturais, ambientais, econômicos e contextuais, indicados no quadro 4. 


\begin{tabular}{|c|c|}
\hline $\begin{array}{l}\text { TIPOS DE } \\
\text { OBSTÁCULOS }\end{array}$ & DESCRIÇÃO \\
\hline Culturais & $\begin{array}{l}\text { Comportamentos adotados pelos atores do processo de transferência de tecnologia (Beesley \& Cooper, } \\
\text { 2008; Caputo et al., 2004; Decter et al., 2007; Elmuti et al., 2005; Yokakul \& Zawdie, 2009), limitações da sua } \\
\text { base de conhecimentos (Caputo et al., 2004; Chen, Duan, Edwards \& Lehaney, 2006) e dificuldades } \\
\text { relacionais (Beesley \& Cooper, 2008; Caputo et al., 2004; Decter et al., 2007; Elmuti et al., 2005; Jagoda, } \\
\text { Maheshwari \& Lonseth, 2010; Lakpetch \& Lorsuwannarat, 2012) }\end{array}$ \\
\hline Cognitivos & $\begin{array}{l}\text { Problemas de relacionamento (Chen et al., 2006; Elmuti et al., 2005; Fernie, Green, Weller \& Newcombe, } \\
\text { 2003; Jagoda et al., 2010; Venters \& Kyriakidou-Zacharoudiou, 2012) ou limitações de conhecimento } \\
\text { (Decter et al., 2007; Jagoda et al., 2010; Jones, 2003) }\end{array}$ \\
\hline Estruturais & $\begin{array}{l}\text { Limitações do receptor (Beesley \& Cooper, 2008; Decter et al., 2007; Jagoda et al., 2010), diferenças } \\
\text { contextuais entre atores (Fernie et al., 2003; Lakpetch \& Lorsuwannarat, 2012; Sawers, Pretorius \& } \\
\text { Oerlemans, 2008; Venters \& Kyriakidou-Zacharoudiou, 2012), riscos da gestão (Philbin, 2008; Venters \& } \\
\text { Kyriakidou-Zacharoudiou, 2012), da operação (Beesley \& Cooper, 2008; Chen et al., 2006; Jagoda et al., } \\
\text { 2010; Lakpetch \& Lorsuwannarat, 2012; Lee \& Win, 2004; Venters \& Kyriakidou-Zacharoudiou, 2012) e da } \\
\text { finalização do processo (Caputo et al., 2004; Elmuti et al., 2005; Lee \& Win, 2004) }\end{array}$ \\
\hline Ambientais & $\begin{array}{l}\text { Dificuldades de acesso a informações (Caputo et al., 2004; Chen et al., 2006; Yokakul \& Zawdie, 2009) e } \\
\text { mudanças ambientais (Elmuti et al., 2005) }\end{array}$ \\
\hline Econômicos & $\begin{array}{l}\text { Necessidade de investimentos (Caputo et al., 2004; Decter et al., 2007; Jagoda et al., 2010) e diferentes } \\
\text { expectativas de resultados gerados (Decter et al., 2007; Guan et al., 2006) }\end{array}$ \\
\hline Contextuais & $\begin{array}{l}\text { Incompatibilidade entre os contextos do emissor e do receptor da tecnologia (Fernie et al., 2003); uso de } \\
\text { sistemas inadequados aos diferentes tipos de tecnologias (Massa \& Testa, 2011); ausência de padrões para } \\
\text { elaboração de projetos (Hagge \& Lappe, 2005). }\end{array}$ \\
\hline
\end{tabular}

\section{Quadro 4-Obstáculos à transferência de tecnologia Fonte: Elaboração própria a partir dos autores referenciados}

Embora haja obstáculos a confrontar, segundo Paula, Danjour, Medeiros e Añez (2015) os benefícios da transferência de tecnologia superam, significativamente, esses eventuais pontos negativos que as inovações em processos podem apresentar. Aliados a este, seguem apontados outros fatores que devem ser considerados para a efetividade da transferência de tecnologia.

\section{- Fatores de efetividade da transferência de tecnologia}

Um dos fatores de efetividade da transferência de tecnologia é a compatibilidade contextual entre emissor e receptor. Para tornar compatíveis os contextos do emissor e do receptor da tecnologia, pode ser adotada uma metodologia para desenvolvimento cooperativo, pautada na adaptação do conhecimento existente no emissor à realidade do receptor, sendo fundamental utilizar sistemas adequados aos diferentes tipos de necessidades tecnológicas (Massa \& Testa, 2011) e padrões para elaboração e implantação de projetos (Hagge \& Lappe, 2005). Fatores de efetividade da transferência de tecnologia identificados na literatura seguem ordenados conforme os atores envolvidos (Quadro 5). 


\begin{tabular}{|c|c|}
\hline $\begin{array}{c}\text { ATORES } \\
\text { ENVOLVIDOS }\end{array}$ & DESCRIÇÃO \\
\hline $\begin{array}{l}\text { Alianças entre } \\
\text { universidade e } \\
\text { empresa }\end{array}$ & $\begin{array}{l}\text { Aumento dos atributos potenciais dos parceiros para formação de alianças, promoção de interface de rede } \\
\text { entre universidades e parceiros, ajuste dos mecanismos de governança e apoio institucional para facilitação } \\
\text { da colaboração (Elmuti et al., 2005; Lakpetch \& Lorsuwannarat, 2012); aumento da consistência da políticas } \\
\text { universitárias, melhoria da acessibilidade das empresas às universidades e motivação dos participantes } \\
\text { (Caputo et al., 2004); estruturação da gestão estratégica e operacional (Perkmann \& Walsh, 2007) }\end{array}$ \\
\hline $\begin{array}{c}\text { Relações entre } \\
\text { empresas }\end{array}$ & $\begin{array}{l}\text { Estabelecimento de relações de confiança entre emissores e receptores de tecnologia, adaptação dos } \\
\text { conteúdos a serem transferidos à realidade da organização receptora, contextualização do conteúdo } \\
\text { explícito e tácito a repassar (Fernie et al., 2003); definição de critérios para medir a similaridade entre } \\
\text { domínios, seleção de tecnologias dos emissores que sejam relevantes para os receptores (Pan \& Yang, 2010) }\end{array}$ \\
\hline MPE & $\begin{array}{l}\text { Adoção de estratégias e de abordagem que levem em conta as características inerentes ao tipo de empresa, } \\
\text { desde a etapa preparatória do processo (Guan et al., 2006; Nunes, Annansingh, Eaglestone \& Wakefield, } \\
\text { 2006; Will, 2008); flexibilidade do projeto para transferência de tecnologia, estruturação da estratégia de } \\
\text { aprendizagem, suporte de sistemas de tecnologia da informação e estabelecimento de cultura da confiança } \\
\text { entre emissor e receptor (Rhodes, Hung, Lok, Lien \& Wu, 2008) }\end{array}$ \\
\hline
\end{tabular}

\section{Quadro 5 - Fatores para efetividade da transferência de tecnologia Fonte: Elaboração própria a partir dos autores referenciados}

Em complemento aos aspectos aqui considerados para promover a efetividade da transferência de tecnologia, Perkmann e Walsh (2007) ressaltam a necessidade de especificar papéis dos atores, como das empresas e universidades, nas redes de relacionamento. Quanto à absorção de conhecimento pelo receptor, é observado que ela é mais influenciada pela intenção que pela habilidade de absorver (O'Dwyer \& O'Flynn, 2005), o que indica a validade de ofertar incentivos aos destinatários dos processos de transferência de tecnologia. Este e outros aspectos devem ser levados em conta no estabelecimento de parcerias para a transferência de tecnologia.

\section{- Parcerias para transferência de tecnologia}

Como muitos processos de transferência de tecnologia envolvem mais de um ator para que se realizem, Elmuti et al. (2005) recomenda a adoção de princípios para a formação de parcerias, tais como: seleção do parceiro, engajamento de pessoas interessadas e inovadoras, suporte a resultados personalizados, ligação entre os projetos e as prioridades da empresa, alinhamento com os recursos organizacionais existentes, foco no valor agregado além do custo despendido, geração de benefícios para ambas as partes, busca e captação de múltiplas cadeias de valor. Considerar estes princípios é um elemento estratégico, na medida em que contribui para motivar os atores ao processo de transferência de tecnologia.

Postos os fatores estratégicos delineados na literatura, seguem apresentados os aspectos pertinentes ao projeto para transferência de tecnologia apontados pelos autores consultados. 


\subsection{Projeto para transferência de tecnologia}

Verifica-se que a literatura aborda aspectos referentes ao projeto para transferência de tecnologia, os quais estão aqui reunidos nas categorias de gestão, mecanismos de relacionamento ou tipos de transação, conteúdo tecnológico, processo operacional, monitoramento do desempenho e análise da viabilidade.

- Gestão da transferência de tecnologia

É relevante a definição de um modus operandi para a transferência de tecnologia, sendo recomendável estabelecer como ocorrerá a gestão estratégica e operacional do projeto. Segundo Philbin (2008), a gestão estratégica deve se desenvolver em quatro níveis, que determinam o engajamento entre os colaboradores e as atividades correspondentes: (1) liderança, (2) programa e negócios, (3) técnico, (4) comercial e de contratos. No nível da liderança devem ser verificadas as implicações estratégicas e questões financeiras globais do projeto. Em seguida, recomenda que sejam estabelecidas as metas do programa de negócios, seus objetivos e programadas as receitas de vendas, segundo as quais se definem as metas técnicas. A abordagem estratégica é finalizada com a definição das questões financeiras, formalização dos termos legais e condições contratuais (Philbin, 2008).

No que tange à gestão operacional do projeto de transferência de tecnologia, segundo Philbin (2008), deve-se considerar os seguintes elementos estruturais: agentes de colaboração, etapas, capital social, missões técnicas e de negócios. As etapas propostas são: mapeamento do terreno, proposição, execução e entrega do trabalho, avaliação dos resultados.

Visto que a transferência de tecnologia pode ocorrer entre diversos atores e em distintos cenários, seguem apresentados mecanismos de relacionamento em que ela se dá: do meio acadêmico para empresas, do setor público para empresa, entre empresas e mediante diversos formatos diferentes dos aqui especificados.

- Mecanismos de relacionamento ou tipos de transação para transferência de tecnologia

A transferência de tecnologia pode partir do meio acadêmico, de empresas, do setor público ou de outras fontes, dirigindo-se aos receptores da tecnologia, conforme variados mecanismos de relacionamento ou tipos de transação (Quadro 6). 


\begin{tabular}{|c|c|}
\hline $\begin{array}{c}\text { ATORES } \\
\text { ENVOLVIDOS }\end{array}$ & MECANISMOS DE RELACIONAMENTO PARA TRANSFERÊNCIA DE TECNOLOGIA \\
\hline $\begin{array}{c}\text { Universidade e } \\
\text { empresa }\end{array}$ & $\begin{array}{l}\text { Visitas dos dirigentes das IES às empresas; participação de empresários em mesas redondas para discussão } \\
\text { curricular e no Conselho Universitário/ Escolar da IES; compartilhamento de equipamentos, sistematização e } \\
\text { suporte à contratação de estagiários, realização de encontros para intercâmbio de informações; estágio } \\
\text { enquanto disciplina; prestação de serviços de cunho tecnológico, como consultorias de resposta rápida de } \\
\text { informação, pesquisas, parcerias de suporte financeiro para o desenvolvimento de projetos e programas de } \\
\text { gestão tecnológica; programas de educação continuada, cursos de extensão, cursos extraordinários e } \\
\text { programas de educação à distância; implantação e gestão de núcleos de desenvolvimento de tecnologia, } \\
\text { incubadoras, parques, polos, agências e seus Núcleos de Inovação Tecnológica (H. C. C. Ferreira, 2009) } \\
\text { Uso do conhecimento científico gerado na instituição acadêmica para criação de empresas de base } \\
\text { tecnológica pelos pesquisadores, desenvolvimento e aproveitamento de direitos de propriedade intelectual } \\
\text { como patentes e outros tipos de registros, transferência por meio de recursos humanos, como cooperação } \\
\text { nos programas de graduação e pós-graduação, treinamento avançado para os profissionais da indústria e } \\
\text { intercâmbio sistemático de pesquisadores entre a indústria e a instituição acadêmica (Debackere, 2000) }\end{array}$ \\
\hline $\begin{array}{c}\text { Relações entre } \\
\text { empresas }\end{array}$ & $\begin{array}{l}\text { Acesso a informações técnicas publicadas na Internet, disseminação e aplicação eficaz do conhecimento e da } \\
\text { tecnologia disponíveis e não amplamente utilizados, aquisição de tecnologia embutida em bens, } \\
\text { componentes ou produtos de capital, cópias e engenharia reversa, licenciamento, assistência técnica, } \\
\text { criação e comercialização de novos conhecimentos e tecnologias; investimento direto estrangeiro, partilha } \\
\text { de liderança entre um país desenvolvido e outro emergente (twinning), aquisição de conhecimento e } \\
\text { tecnologia do exterior para o uso e adaptação local, estudos no exterior, parcerias para treinamento } \\
\text { cooperativo e aprendizagem a distância (Rodriguez, Dahlman \& Salmi, 2008) }\end{array}$ \\
\hline
\end{tabular}

\section{Quadro 6 - Mecanismos de relacionamento para transferência de tecnologia Fonte: Elaboração própria a partir dos autores referenciados}

Segundo Mengoni e Sami (2007), uma tipologia de transferência de tecnologia é a interação entre universidades e empresas para definição da grade curricular dos cursos que irão formar os profissionais que posteriormente atuarão no mercado. Além disso, a presença de profissionais do mercado em ações da academia, como realização de palestras em eventos universitários, tende a contextualizar os alunos às demandas do mercado. Ainda quanto à inter-relação entre universidades e indústrias, mas também contando com a participação do governo como atores, Feng, Ding e Sun (2010) apresentam a tipologia da hélice tríplice, capaz de acelerar a geração de inovações e sua oferta ao mercado pela interação de atores dos três grupos (quadro 7).

\begin{tabular}{c|l|l}
\hline $\begin{array}{c}\text { TIPOS DE } \\
\text { TRANSFERÊNCIA DE } \\
\text { TECNOLOGIA }\end{array}$ & $\begin{array}{c}\text { FORMAS DE } \\
\text { COOPERAÇÃo }\end{array}$ & \multicolumn{1}{c|}{ CARACTERÍSTICAS } \\
\hline & $\begin{array}{l}\text { Desenvolvimen } \\
\text { to cooperativo }\end{array}$ & $\begin{array}{l}\text { Complexidade tecnológica; desenvolvimento paralelo pelos atores; combinação } \\
\text { de abordagem técnica e mercadológica; impossibilidade de desenvolvimento } \\
\text { individual pelos atores. }\end{array}$ \\
\cline { 2 - 4 } $\begin{array}{c}\text { Colaboração focada } \\
\text { nos objetivos das } \\
\text { empresas }\end{array}$ & $\begin{array}{l}\text { Transferência } \\
\text { técnica }\end{array}$ & $\begin{array}{l}\text { Investimentos realizados pelas universidades e institutos de pesquisa e teste dos } \\
\text { projetos piloto executados pelas empresas. }\end{array}$ \\
\cline { 2 - 4 } & $\begin{array}{l}\text { Fomento de } \\
\text { talentos }\end{array}$ & $\begin{array}{l}\text { Emissão de certificados por universidades para profissionais que lhes são } \\
\text { enviados para capacitação pelas empresas; desenvolvimento colaborativo de } \\
\text { bases de talentos de graduação e pós-doutorado entre universidades e } \\
\text { empresas; seleção de profissionais realizada pelas universidades para as } \\
\text { empresas. }\end{array}$ \\
\hline & $\begin{array}{l}\text { Instituições e } \\
\text { institutos de } \\
\text { pesquisa e } \\
\text { centros de }\end{array}$ & $\begin{array}{l}\text { Manutenção permanente da vantagem competitiva das empresas, em termos } \\
\text { de tecnologia; investimento conjunto de setores industriais nacionais para } \\
\text { promoção do apoio a realizações científicas; implantação de recursos das } \\
\text { indústrias, universidades e institutos de pesquisa em centros de engenharia }\end{array}$ \\
\hline
\end{tabular}




\begin{tabular}{|c|c|c|}
\hline \multirow{3}{*}{$\begin{array}{l}\text { Construção em uma } \\
\text { nova entidade } \\
\text { criada pelos três } \\
\text { atores }\end{array}$} & engenharia & industrial, para configurar institutos de alto nível investigativo. \\
\hline & $\begin{array}{l}\text { Novas } \\
\text { empresas de } \\
\text { alta tecnologia }\end{array}$ & $\begin{array}{l}\text { Criação e operação conjunta de novas empresas de alta tecnologia por } \\
\text { Universidades e institutos de pesquisa que aplicam talentos técnicos, e } \\
\text { empresas que utilizam o seu capital em equipamentos, mercado e produção } \\
\text { operação conjunta e investimento em tecnologia. }\end{array}$ \\
\hline & $\begin{array}{l}\text { Parques } \\
\text { científicos }\end{array}$ & $\begin{array}{l}\text { Criação de ambientes de pesquisa em regiões geográficas que reúnem } \\
\text { universidades e empresas. }\end{array}$ \\
\hline \multirow[t]{2}{*}{$\begin{array}{l}\text { Cooperação para } \\
\text { industrialização } \\
\text { independente }\end{array}$} & $\begin{array}{l}\text { Em faculdades } \\
\text { e universidades }\end{array}$ & $\begin{array}{l}\text { Integração direta entre faculdades e universidades para desenvolvimento da } \\
\text { própria investigação científica, desenvolvimento técnico, julgamento, produção } \\
\text { e comercialização. Faculdades e universidades atraem capital para criar } \\
\text { institutos de pesquisa e iniciar empresas de gestão escolar e alta tecnologia. }\end{array}$ \\
\hline & $\begin{array}{l}\text { Em institutos } \\
\text { de pesquisa }\end{array}$ & $\begin{array}{l}\text { Integração direta entre indústrias e institutos de pesquisa para condução } \\
\text { independente de investigação científica, desenvolvimento, produção } \\
\text { experimental e marketing, eliminando elos intermediários e agilizando a criação } \\
\text { de produtos a partir de experimentos científicos. }\end{array}$ \\
\hline
\end{tabular}

\section{Quadro 7 - Tipologias de Transferência de Conhecimento na Hélice Tríplice} Fonte: Elaboração própria a partir de (Feng et al., 2010)

Um elemento complementar e que potencializa os projetos da hélice tríplice se refere ao efeito da geografia no desempenho macroeconômico, o qual foi comprovado por Varga e Schalk (2006), mediante a aplicação do modelo EcoRET. Embora tenha identificado efeito positivo da proximidade geográfica, os resultados alcançados pelos autores foram variados nos diversos ambientes pesquisados, requerendo estudos mais detalhados. Döring e Schnellenbach (2006) associam desenvolvimento regional sustentável com transbordamento de conhecimento em aglomerados espaciais, relatando que os resultados identificados são positivos, embora variem conforme os tipos de conhecimento, as dimensões espaciais, os mecanismos de integração geográfica e as condições estruturais da divulgação do conhecimento. Além de também identificarem a proximidade geográfica como elemento relevante para a transferência de tecnologia, Santoro e Gopalakrishnan (2001) destacaram a flexibilidade das políticas universitárias como fator importante para obtenção de licenças e patentes. Do mesmo modo, Agrawal (2001) destaca a importância da proximidade espacial entre empresas e universidades, em relação ao desempenho da transferência de conhecimento, acrescentando ainda fatores complementares, como diferentes vias de transferência entre universidades e empresas, tais como publicações, patentes e consultorias. Menciona ainda questões relacionadas com a universidade, como estratégias de licenciamento, incentivos e políticas para registro de patentes por professores.

Os mecanismos citados compreendem a transferência de conteúdos tecnológicos, os quais podem apresentar diversos formatos.

- Conteúdo tecnológico

O conteúdo tecnológico a ser transferido pode se caracterizar quanto à tipologia, ao formato que apresenta, à abrangência dos objetivos que possui e a orientação para seu uso.

No que se refere à tipologia, a tecnologia é caracterizada como de produto ou de processo, sendo essa última subdividida em tecnologia física - definição e preparação das operações e sua sequência - e tecnologia de gestão - técnicas, instrumentos ou estratégias 
utilizadas pelos administradores para controlar e aperfeiçoar o processo de produção e de trabalho (ANPROTEC \& SEBRAE, 2002; Faria, 1997; Maximiano, 2012). No tocante à forma por meio da qual é disponibilizada, pode ser materializada, documentada ou imaterial (Reis, 2008) ou ainda se apresentar como bens, recursos humanos, tecnologia da informação ou formas de organização e gestão (Arnoletto, 2007). Quanto à abrangência dos objetivos aos quais se direciona, assume as denominações de convencional ou adequada. A tecnologia pode ainda assumir orientação para uso instrumental, cognitiva ou de enfoque sistêmico (Arnoletto, 2007).

Destaca-se que "conhecimento" é um dos formatos assumidos pela tecnologia a ser transferida, estando implícito na expressão "transferência de tecnologia" adotada no artigo. Assim, a expressão "transferência de tecnologia" engloba "transferência de conhecimento", dentre as demais formas passíveis de serem assumidas pela tecnologia. Informações referentes ao processo operacional da transferência de tecnologia seguem apresentados.

- Processo operacional da transferência de tecnologia

Conforme observado, o processo de transferência de tecnologia ocorre desde um emissor até um receptor, por meio de mecanismos de relacionamento que configuram um canal. É possível que o canal onde se desenvolva o processo de transferência de tecnologia apresente diferentes configurações, distintas entre si conforme tipos e quantidades de etapas.

Alguns componentes são essenciais ao processo de transferência de tecnologia, como o preparo da infraestrutura e dos recursos humanos (Tahmooresnejad, Shafia \& Salami, 2011), referentes ao emissor, aos agentes de transferência e ao receptor da tecnologia transferida.

Quanto à execução do processo de transferência de tecnologia, é necessário definir a sequência operacional do modelo a adotar, considerando-se que poderá ocorrer desde um emissor até um receptor, por meio de mecanismos de relacionamento que configuram um canal, o qual assume diferentes configurações, distintas entre si conforme tipos e quantidades de etapas (Hajri \& Hasan, 2011).

No que tange à aquisição, uma vez caracterizada a tecnologia a ser transferida, é observado que ela pode advir de diversos tipos de fontes e muitos dos estudos sobre o tema apresentam emissores potenciais (quadro 12). De acordo com a forma como são disponibilizadas, os tipos de fontes de tecnologia podem se classificar em: fontes de informação abertas, que não exigem qualquer pagamento; tecnologia a ser adquirida mediante compra, sem interação com a fonte; inovação cooperativa, mediante cooperação ativa da empresa em atividades tecnológicas, podendo compreender a compra de conhecimentos e de tecnologia (OCDE, 2005).

No que se refere aos objetivos, a aquisição de conhecimento pelas MPEs usualmente é dirigida à obtenção de resultados mensuráveis (Thorpe et al., 2005), seja o conteúdo transferido de ordem instrumental ou cognitiva (Rottman, 2008). 
Com relação à apropriação pelo receptor, uma vez em seu destino, a tecnologia desenvolvida é testada, difundida, adotada e implantada. A implantação corresponde às práticas adotadas pelos receptores para apropriação da nova tecnologia recebida, e se dá mediante as etapas de introdução, absorção, adaptação, aplicação, aperfeiçoamento e inovação (Cysne, 2005; J. Ferreira et al., 2012; Lima, 2004; Mattos \& Guimarães, 2013; Takahashi, 2005).

Para que o receptor incorpore a tecnologia a ele transferida, observa-se a tendência do uso da segunda geração da gestão do conhecimento (Thorpe et al., 2005), por meio de sistemas adaptativos complexos, nos quais os novos conhecimentos são integrados na organização, mediante articulação com estruturas existentes e em funcionamento (Sherif, 2006) Este tipo de abordagem propicia o retorno da tecnologia incorporada, a qual decorre da eficácia da aprendizagem organizacional (Falconer, 2006; Fernie et al., 2003).

É necessário gerenciar, no interior das organizações receptoras, a apropriação do conhecimento que configura a tecnologia transferida ou a acompanha, havendo situações em que a própria aquisição de conhecimentos demanda gerenciamento especializado, como quando ocorre por meio eletrônico, também denominado e-learning (Lin, Fang, Fang \& Tsai, 2009). Em processos de transferência de tecnologia é esperado que os receptores construam capacidades por meio do aprendizado (Perkmann \& Walsh, 2007), a partir do qual será possível monitorar a evolução do conhecimento recebido e incorporado às rotinas organizacionais. A verificação da incorporação das capacidades tecnológicas decorre da sistemática de avaliação do desempenho adotada pelo projeto de transferência de tecnologia.

- Monitoramento e avaliação do desempenho

Para que o processo de transferência seja considerado efetivo, fazem-se necessários o recebimento e o uso da tecnologia pelo receptor, gerando os efeitos esperados e tornando-se ela parte da rotina organizacional. Como possíveis resultados estão mudanças de cunho tecnológico, econômico e social, aumento da competitividade e do impacto da nova tecnologia na cadeia de negócios (Saab, Gimenez \& Ribeiro, 2000).

A aferição dos resultados alcançados por meio da transferência de tecnologia requer a definição de indicadores que permitam monitorar e avaliar o desempenho. No entanto, medir a capacidade tecnológica é mais complexo que medir fatores econômicos e sociais, devido à heterogeneidade dos seus componentes $A$ mensuração da transferência de tecnologia se desenvolve conforme diferentes sistemas de abordagem à inovação, que variam de acordo com os critérios adotados pelas entidades que realizam a medição. Alguns exemplos são indicadores de geração de invenções e inovações, mas também indicadores de aplicação, divulgação e disseminação da tecnologia transferida. Isto decorre do fato de que alguns atores podem ser fortes produtores de novos conhecimentos, mas fracos na sua aplicação para a produção, enquanto outros podem se beneficiar muito do conhecimento proveniente de outras fontes (Archibugi \& Coco, 2005). 
Uma vez que a tecnologia transferida possui forte conteúdo informacional, é recomendada a adoção de indicadores referentes a criação, aquisição, transferência, implantação de tecnologia, visando possibilitar o acompanhamento do grau de inovação em vários setores e identificar os fatores que facilitam a transferência e adoção de conhecimento em maior ou menor grau (Beesley \& Cooper, 2008). Quanto aos indicadores da transferência de tecnologia, Beesley e Cooper (2008) destacam as limitações de adotar como índice a medição da quantidade de publicações e apresentações em conferências e seminários, uma vez que se trata de uma estratégia unilateral de comunicação, em que as impressões do receptor não são registradas e a recepção do aprendizado está limitada pela força da sua intenção de aprender e por sua interpretação subjetiva. A definição dos indicadores que possibilitarão mensurar o alcance da transferência de tecnologia é um dos elementos a serem considerados na análise da viabilidade do processo proposto.

- Viabilidade

A análise da viabilidade da transferência de tecnologia é recomendada por Caputo et al. (2004), devendo ocorrer antes que o processo de transferência seja iniciado, possibilitando que sejam ativadas as medidas cabíveis para solucionar as restrições identificadas. Os processos de transferência de tecnologia envolvem a realização de ações que implicam despesas, podendo ser necessária a presença de agentes financiadores (Jones, 2003). A viabilidade da transferência de tecnologia decorre ainda do processo de adaptação dos conteúdos a serem transferidos para a realidade da empresa receptora (Fernie et al., 2003). Todavia, os recursos financeiros e tecnológicos são apenas dois dos componentes viabilizadores do processo, ao lado do estabelecimento de relação de confiança entre emissor e receptor, e de requisitos operacionais, econômicos e legislativos (Fernie et al., 2003).

\section{CONCLUSÕES}

Neste trabalho foram identificadas abordagens presentes na literatura sobre transferência de tecnologia, sendo estruturada uma taxonomia a partir dos principais conceitos e componentes referentes à temática. Os componentes da estrutura taxonômica elaborada são: atores, estratégia e projeto para transferência de tecnologia. Observa-se que os atores do processo de transferência de tecnologia são o emissor ou fonte, o receptor ou destinatário, agentes de colaboração e apoio. Quanto à estratégia adotada para realizar a transferência de tecnologia, a literatura indica como relevante definir governança, motivação dos atores, obstáculos, fatores de efetividade e parcerias. Verifica-se a presença dos seguintes componentes em um projeto de transferência de tecnologia: modelo de gestão, mecanismos de relacionamento ou tipos de transação, conteúdo tecnológico, processo operacional, viabilidade, monitoramento e avaliação do desempenho.

Observa-se que as diferentes tipologias de transferência de tecnologia apresentadas na literatura se inserem nos contextos das relações do meio acadêmico para empresas, do 
setor público para empresa, entre empresas e mediante diversos formatos diferentes dos aqui especificados, sendo fundamentais os papeis dos atores da transferência: receptor, emissor e facilitador. $\mathrm{Na}$ atualidade, destacam-se nos processos de transferência de tecnologia os modelos de inter-relação denominados hélice tríplice - empresas, academia e governo - e hélice quádrupla - empresas, academia, governo e facilitadores. Este destaque decorre da capacidade dos modelos de hélice promoverem a transferência de tecnologia para grupos de receptores, simultaneamente, maximizando o retorno dos esforços, mediante o alcance ao conhecimento por diversos destinatários.

É destacado o papel do receptor para a efetividade da transferência de tecnologia, visto que o êxito do processo decorre da capacidade do destinatário do conhecimento absorver e implantar a nova tecnologia, assim como de monitorar o alcance dos resultados desejados. A capacidade de absorção se relaciona com aspectos relativos à compatibilidade da tecnologia transferida com a infraestrutura existente no receptor e ainda à motivação e nível educacional da equipe. Restrições do receptor, como limitações da sua base de conhecimentos, dificuldades relacionais, diferenças contextuais entre atores, riscos da gestão, operação e finalização podem comprometer o alcance dos resultados pretendidos. O emissor possui papel preponderante nas situações em que a transferência de tecnologia prescinde da sua participação ativa no processo, figurando como fonte e responsável pela geração da tecnologia a ser transferida e das instruções para absorção e uso pelo receptor, sem que, no entanto, participe interativamente do processo de implantação. Já a atuação dos facilitadores ou agentes de apoio, destaca-se nos casos em que existem óbices na relação entre emissor e receptor difíceis de serem superados sem a participação e uma entidade externa, seja para promover a articulação entre os atores, prover condições financeiras, ou mesmo propor, criar e implantar políticas públicas direcionadas à criação de um ambiente propício à transferência de tecnologia.

Este trabalho representa um avanço científico ao endereçar a consolidação dos componentes da transferência de tecnologia, abordados de modo disperso e pontual na literatura revisada. Recomenda-se a continuidade do estudo sobre o tema, mediante concepção de uma metodologia para transferência de tecnologia que contemple todos os aspectos inerentes ao processo aqui apresentados. Sugere-se ainda a realização de pesquisa versando sobre a revisão de modelos para transferência de tecnologia, verificando neles a presença dos componentes aqui identificados e de outros mais não detectados nesta revisão.

\section{REFERÊNCIAS}

Agrawal, A. K. (2001). University-to-industry knowledge transfer: literature review and unanswered questions. International Journal of Management Reviews, 3(4), 285-302. doi:10.1111/14682370.00069 
Albors-Garrigos, J., Zabaleta, N. \& Ganzarain, J. (2010). New R\&D management paradigms: rethinking research and technology organizations strategies in regions. R\&D Management, 40(5), 435454. doi:10.1111/j.1467-9310.2010.00611.x

ANPROTEC \& SEBRAE. (2002). Glossário dinâmico de termos na área de tecnópoles, parques tecnológicos e incubadoras de empresas (A. M. C. Baêta \& R. M. N. Silva Eds.). Brasília.

Archibugi, D. \& Coco, A. (2005). Measuring technological capabilities at the country level: A survey and a menu for choice. Research Policy, 34(2), 175-194. doi:10.1016/j.respol.2004.12.002

Arnoletto, E. J. (2007). El impacto de la tecnología en la transformación del mundo. Córdoba, Argentina: Edición electrónica gratuita. Texto completo em http://www.eumed.net/librosgratis/2007c/333/indice.htm.

Bauer, S. M. (2003). Demand Pull Technology Transfer Applied to the Field of Assistive Tech. The Journal of Technology Transfer, 28(3), 285-303. doi:10.1023/A:1024953130221

Beesley, L. G. A. \& Cooper, C. (2008). Defining knowledge management (KM) activities: towards consensus. Journal of Knowledge Management, 12(3), 48-62. doi:10.1108/13673270810875859

Burgelman, R. A., Christensen, C. M. \& Wheelwrigth, S. C. (2012). Gestão Estratégica da Tecnologia e da Inovação: Conceitos e Soluções (5a. ed.). Porto Alegre, Brasil: AMGH.

Caputo, A. C., Cucchiella, F., Fratocchi, L., Pelagagge, P. M. \& Scacchia, F. (2004). Analysis and evaluation of e-supply chain performances. Industrial Management \& Data Systems, 104(7), 546-557. doi:10.1108/02635570410550214

Chen, S., Duan, Y., Edwards, J. S. \& Lehaney, B. (2006). Toward understanding inter-organizational knowledge transfer needs in SMEs: insight from a UK investigation. Journal of Knowledge Management, 10(3), 6-23. doi:10.1108/13673270610670821

Cysne, M. R. F. P. (2005). Transferência de tecnologia entre a universidade e a indústria. Encontros Bibli: Revista Eletrônica de Biblioteconomia e Ciência da Informação, 10(20), 54-74.

Debackere, K. (2000). Managing academic R\&D as a business at K.U. Leuven: context, structure and process. R\&D Management, 30(4), 323-328. doi:10.1111/1467-9310.00186

Decter, M., Bennett, D. \& Leseure, M. (2007). University to business technology transfer-UK and USA comparisons. Technovation, 27(3), 145-155. doi:10.1016/j.technovation.2006.02.001

Döring, T. \& Schnellenbach, J. (2006). What do we know about geographical knowledge spillovers and regional growth?: A survey of the literature. Regional Studies, 40(3), 375-395. doi:10.1080/00343400600632739

Elmuti, D., Abebe, M., Nicolosi, M. \& Dealtry, R. (2005). An overview of strategic alliances between universities and corporations. Journal of Workplace Learning, 17(1/2), 115-129. doi:10.1108/13665620510574504

Falconer, L. (2006). Organizational learning, tacit information, and e-learning: a review. The Learning Organization, 13(2), 140-151. doi:10.1108/09696470610645476

Faria, J. H. (1997). Tecnologia e processo de trabalho (2a. ed.). Curitiba: UFPR.

Feng, C., Ding, M. \& Sun, B. (2010). Selection of Modes of Cooperation among Industries, Universities and Research Institutes. Asian Social Science, 6(10), 97-101. doi:0.5539/ass.v6n10p97

Fernie, S., Green, S. D., Weller, S. J. \& Newcombe, R. (2003). Knowledge sharing: context, confusion and controversy. International Journal of Project Management, 21(3), 177-187. doi:10.1016/S0263-7863(02)00092-3

Ferreira, H. C. C. (2009). Gestão e Transferência de Tecnologia entre Instituições de Ensino Superior particulares e empresas. (Dissertação de Mestrado), UTFPR, Ponta Grossa, Brasil.

Ferreira, J., Azevedo, S. G., Raposo, M. L., Lee, C. S., Ho, J. C. \& Niu, K. H. (2012). Specialization of regional clusters and innovative behavior: a case study. Competitiveness Review, 22(2), 147169. doi:10.1108/10595421211205985 
Guan, J. C., Mok, C. K., Yam, R. C. M. \& Pun, K. S. C. F. (2006). Technology transfer and innovation performance: Evidence from Chinese firms. Technological Forecasting and Social Change, 73(6), 666-678. doi:10.1016/j.techfore.2005.05.009

Hagge, L. \& Lappe, K. (2005). Sharing Requirements Engineering experience using patternse. IEEE Software, 22(1), 24-31. doi:10.1109/MS.2005.17

Hajri, A. S. A. \& Hasan, M. (2011). Logistics technology transfer process model. Int'l Technology Management Conference, 944-956. doi:10.1109/itmc.2011.5995989

Jagoda, K., Maheshwari, B. \& Lonseth, R. (2010). Key issues in managing technology transfer projects: Experiences from a Canadian SME. Management Decision, 48(3), 366-382. doi:10.1108/00251741011037747

Jones, O. (2003). The persistence of autocratic management in small firms: TCS and organisational change. International Journal of Entrepreneurial Behavior \& Research, 9(6), 245-267. doi:10.1108/13552550310501365

Kremer, A. (2007). Desenvolvimento sustentável através de transferência de tecnologia: o caso do município de castro no estado do Paraná. (Master), UTFPR, Ponta Grossa, Brasil. Recuperado de

http://www.dominiopublico.gov.br/pesquisa/DetalheObraForm.do?select_action=\&co_obra= 128191

Lakpetch, P. \& Lorsuwannarat, T. (2012). Knowledge transfer effectiveness of university-industry alliances. International Journal of Organizational Analysis, 20(2), 128-186. doi:10.1108/19348831211227819

Lee, J. \& Win, H. N. (2004). Technology transfer between university research centers and industry in Singapore. Technovation, 24(5), 433-442. doi:10.1016/S0166-4972(02)00101-3

Lima, I. A. (2004). Estrutura de referência para a transferência de tecnologia no âmbito da cooperação universidade-empresa: estudo de caso no CEFET-PR. (Tese Doutorado), UFSC, Florianópolis, SC. Recuperado de https://repositorio.ufsc.br/handle/123456789/87075?show=full

Lin, J. L., Fang, S.-C., Fang, S.-R. \& Tsai, F.-S. (2009). Network embeddedness and technology transfer performance in R\&D consortia in Taiwan. Technovation, 29(11), 763-774. doi:10.1016/j.technovation.2009.05.001

Massa, S. \& Testa, S. (2011). Knowledge domain and innovation behaviour: A framework to conceptualize KMSs in small and medium enterprises. Vine, 41(4), 483-504. doi:10.1108/03055721111188557

Mattos, J. R. L. \& Guimarães, L. S. (2013). Gestão da Tecnologia e Inovação: Uma Abordagem Prática (2a. ed.). São Paulo, Brasil: Saraiva.

Maximiano, A. C. A. (2012). Teoria Geral da Administração - da Revolução Urbana À Revolução Digital (7a. ed.). São Paulo: Atlas.

Mengoni, L. \& Sami, M. (2007). Cooperation Between University and Industries in Organizing a 'Diploma Universitario' Curriculum: The Politecnico di Milano-Assolombarda Experience. European Journal of Engineering Education, 23(4), 423-429. doi:10.1080/03043799808923520

Noronha, D. P. \& Ferreira, S. M. S. P. (2000). Revisões de literatura. In B. V. C. Campello \& J. M. Kremer (Eds.), Fontes de informação para pesquisadores e profissionais (pp. 191-198). Belo Horizonte, Brasil: UFMG.

Nunes, M. B., Annansingh, F., Eaglestone, B. \& Wakefield, R. (2006). Knowledge management issues in knowledge-intensive SMEs. Journal of Documentation, 62(1), 101-119. doi:10.1108/00220410610642075

O'Dwyer, M. \& O'Flynn, E. (2005). MNC-SME strategic alliances - A model framing knowledge value as the primary predictor of governance modal choice. Journal of International Management, 11(3), 397-416. doi:10.1016/j.intman.2005.06.006 
OCDE. (2005). Manual de Oslo. Diretrizes para coleta e interpretação de dados sobre inovação (3a ed.): OCDE. EUROSTAT. FINEP.

Pan, S. J. \& Yang, Q. (2010). A Survey on Transfer Learning. IEEE TRANSACTIONS ON KNOWLEDGE AND DATA ENGINEERING, 22(10), 1345 - 1359. doi:10.1109/TKDE.2009.191

Paula, L. P. D., Danjour, M. F., Medeiros, B. C. \& Añez, M. E. M. (2015). Inovações em processos de tecnologia: Um estudo de caso em uma empresa de contabilidade da cidade do Natal/RN. Holos, 31(6), 196-209. doi:10.15628/holos.2015.3200

Perkmann, M. \& Walsh, K. (2007). University Industry Relationships and Open Innovation: Towards a Research Agenda. International Journal of Management Reviews, 9(4), 259-280. doi:10.1111/j.1468-2370.2007.00225.x

Philbin, S. (2008). Process model for university-industry research collaboration. European Journal of Innovation Management, 11(4), 488-521. doi:10.1108/14601060810911138

Pires, E. A. \& Quintella, C. M. A. L. T. (2015). Política de Propriedade Intelectual e Transferência de Tecnologia nas universidades: Uma perspectiva do NIT da Universidade Federal do Recôncavo da Bahia. Holos, 31(6), 178-195. doi:10.15628/holos.2015.3600

Reis, D. R. (2008). Gestão da Inovação Tecnológica (2a. ed.). São Paulo, Brasil: Manole.

Reisman, A. (2005). Transfer of technologies: a cross-disciplinary taxonomy. Omega, 33(3), 189-202. doi:10.1016/j.omega.2004.04.004

Rhodes, J., Hung, R., Lok, P., Lien, B. Y. H. \& Wu, C. M. (2008). Factors influencing organizational knowledge transfer: implication for corporate performance. Journal of Knowledge Management, 12(3), 84-100. doi:10.1108/13673270810875886

Rodrigues, F. R. M. (2008). Diretrizes para minimizar os impactos negativos de um processo de transferência de tecnologia: um estudo de caso Brasil-México. (Dissertação de Mestrado), UTFPR, Curitiba, Brasil.

Rodrigues, F. R. M. \& Estorilio, C. C. A. (2012). Diretrizes para prevenir problemas em processos de transferência de tecnologia: estudo de caso Brasil-México. Revista Produção Online, 12(4).

Rodriguez, A., Dahlman, C. \& Salmi, J. (2008). Conhecimento e inovação para a competitividade (CNI, Trans.). Brasília: CNI.

Rottman, J. W. (2008). Successful knowledge transfer within offshore supplier networks: a case study exploring social capital in strategic alliances. Journal of Information Technology, 23, 31-43. doi:10.1057/palgrave.jit.2000127

Saab, W. G., Gimenez, L. C. \& Ribeiro, R. (2000). E-business: O uso corporativo da Internet. Recuperado

de http://www.bndes.gov.br/SiteBNDES/bndes/bndes_pt/Institucional/Publicacoes/Consulta_Exp ressa/Setor/Comercio_e_Servicos/200006_9.html

Santoro, M. D. \& Gopalakrishnan, S. (2001). Relationship Dynamics between University Research Centers and Industrial Firms: Their Impact on Technology Transfer Activities. The Journal of Technology Transfer, 26(1), 163-171. doi:10.1023/A:1007804816426

Sawers, J. L., Pretorius, M. W. \& Oerlemans, L. A. G. (2008). Safeguarding SMEs dynamic capabilities in technology innovative SME-large company partnerships in South Africa. Technovation, 28(4), 171-182. doi:10.1016/j.technovation.2007.09.002

Sherif, K. (2006). An adaptive strategy for managing knowledge in organizations. Journal of Knowledge Management, 10(4), 72-80. doi:10.1108/13673270610679372

Tahmooresnejad, L., Shafia, M. A. \& Salami, R. (2011). Identifying Impact Factors in Technology Transfer with the Aim of Technology Localization. International Journal of Social, Behavioral, Educational, Economic, Business and Industrial Engineering, 5(5), 531-535.

Takahashi, V. P. (2005). Transferência de conhecimento tecnológico: estudo de múltiplos casos na indústria farmacêutica. Gestão \& Produção, 12(2), 255-269. doi:10.1590/S0104$530 \times 2005000200009$ 
Thorpe, R., Holt, R., Macpherson, A. \& Pittaway, L. (2005). Using knowledge within small and mediumsized firms: A systematic review of the evidence. International Journal of Management Reviews, 7(4), 257-281. doi:10.1111/j.1468-2370.2005.00116.x

Varga, A. \& Schalk, H. J. (2006). Macroeconomic effects of the geography of technological change. Paper presented at the DIME workshop on Dynamics of Knowledge Accumulation, Competitiveness, Regional Cohesion and Economic Policies, 2 - 4 February 2006, WIIW, Vienna.

Varsakelis, N. C. (2006). Education, political institutions and innovative activity: A cross-country empirical investigation. Research Policy, 35(7), 1083-1090. doi:10.1016/j.respol.2006.06.002

Venters, W. \& Kyriakidou-Zacharoudiou, A. (2012). Interventionist grid development projects: a research framework based on three frames. Information Technology and People, 25(3), 300326. doi:10.1108/09593841211254349

Will, M. (2008). Talking about the future within an SME?: Corporate foresight and the potential contributions to sustainable development. Environmental Management and Health, 19(2), 234-242. doi:10.1108/14777830810856618

Yokakul, N. \& Zawdie, G. (2009). The Role of Triple Helix for Promoting Social Capital, Industrial Technology and Innovation in the SME Sector in Thailand. Science Technology Society, 14(1), 93-117. doi:10.1177/097172180801400104 